\title{
Da promessa de gênero à interpretação reflexiva: perspectivas para a análise das narrativas televisivas
}

\section{Simone Maria Rocha e Ângela Cristina Salgueiro Marques}

\section{Resumo}

Este artigo apresenta uma proposta de análise integrada de produtos televisivos, enfocando as diferentes dimensões do processo comunicativo: produção, produto e recepção. Procuramos evidenciar as interlocuções entre elas a partir da abordagem metodológica que articula: a) análise de conteúdo e análise de gênero televisivo e b) análise de recepção de um produto midiático em grupos de discussão. Empiricamente, empregamos nossa proposta ao gênero teledramaturgia, concentrando-nos nas posições de sujeito (HALL, 2000) construídas pelas narrativas midiáticas acerca dos moradores de favelas brasileiras. As três dimensões analíticas foram acionadas com o propósito de compreender os modos de apresentação dos sujeitos moradores e 0 lugar das favelas naquelas narrativas, bem como de estudar as interpretações que os sujeitos produzem. Analisamos a série Cidade dos Homens (Rede Globo, 2002) e realizamos grupos de discussão com moradores de favelas do Rio de Janeiro e de Belo Horizonte.

\section{Palavras-chave}

Processo comunicativo. Metodologia integrada. Narrativas televisivas. Posições de sujeito.

\section{Simone Maria Rocha | smarocha@ig.com.br}

Doutora em Comunicação e Cultura pela Universidade Federal do Rio de Janeiro - UFRJ. Professora do Programa de Pós-Graduação em Comunicação Social da Universidade Federal de Minas Gerais - UFMG.

Ângela Cristina Salgueiro Marques | angelasalgueiro@gmail.com Doutora em Comunicação Social pela Universidade Federal de Minas Gerais - UFMG. Membro do Groupe de Recherche sur les Enjeux de la Communication (GRESEC)/Université Stendhal - Grenoble 3.

\section{Introdução}

Compreender e explorar o processo

comunicacional constituído a partir da articulação dos sentidos produzidos em diferentes momentos da produção e da recepção de um produto televisivo requer a elaboração de metodologia capaz de evidenciar as características desses momentos, reconhecendo o papel que cada uma desempenha no fenômeno como um todo. Os valores, crenças e opiniões são frutos do diálogo que se estabelece entre esses dois processos. Acreditamos que o lugar da comunicação é a interseção entre as estruturas e linguagens da produção e as percepções mais sensíveis da recepção.

As dimensões da produção e do produto e da recepção influenciam-se reciprocamente e a interseção entre elas se dá no processo de produção de sentido, ou seja, quando as linguagens se aproximam ou se estranham, quando o receptor apreende reflexivamente um produto cultural. Elas "não são, portanto, idênticas, mas estão relacionadas: são momentos diferenciados dentro da totalidade 
formada pelas relações sociais do processo comunicativo como um todo" (HALL, 2003, p. 390). Podemos, assim, considerar 0 processo comunicativo como um processo de intersecção, articulação e permanente diálogo entre a produção, a configuração das mensagens em torno do produto e da recepção, auxiliando no entendimento cada vez maior da complexidade do fenômeno comunicacional e o papel que os media aí exercem.

Sob esse viés, procuramos evidenciar tais interlocuções a partir de uma metodologia que articula: a) análise de conteúdo e análise de gênero televisivo e b) análise de recepção de um produto mediático em grupos de discussão. Empiricamente, empregamos nossa proposta ao gênero televisivo teledramaturgia, concentrando-nos nas posições de sujeito ${ }^{1}$

(HALL, 2000) forjadas nas narrativas mediáticas acerca dos moradores de favelas brasileiras. Deste modo, as três dimensões analíticas foram acionadas com o propósito de compreender os modos de apresentação dos sujeitos moradores e o lugar das favelas naquelas narrativas, bem como de estudar as interpretações que os sujeitos produzem em relação a essas representações.

\section{Análise de gênero televisivo e análise de conteúdo: proposta metodológica integrada}

\subsection{Gênero televisivo como chave de leitura}

No Brasil, pelo menos duas iniciativas procuram desenvolver análises sobre televisão tomando por base a noção de gênero televisivo a partir de duas matrizes distintas: uma vinculada à tradição dos cultural studies e outra vinculada aos estudos de gêneros na perspectiva da análise semiótica da produção e recepção mediática. Na primeira, o Grupo de Pesquisa de Análise de Telejornais (GPTV/PPGCOM/UFBA) tem-se voltado para a análise de telejornais e procura associar aos estudos de gênero o conceito de modos de endereçamento (GOMES, 2006). Quanto ao gênero, assim o descreve Itânia Gomes:

Gênero televisivo é um modo de situar a audiência televisiva, em relação a um programa, em relação ao assunto nele tratado e em relação ao modo como o programa se destina ao público. Nessa perspectiva, gênero é uma estratégia de interação, e investir numa abordagem dos gêneros televisivos pode significar ultrapassar a dicotomia entre análise do produto televisivo e análise dos contextos sociais de sua recepção (2002, p. 167).

A perspectiva dos cultural studies adota o gênero como uma relação social, como o uso que 0 telespectador faz de um certo produto. Segundo Jesús Martín-Barbero:

Este é um conceito central proposto por Stuart Hall (2000) em seu itinerário em torno da discussão sobre identidades. Hall entende que as identidades se formam num ponto de sutura entre os discursos e práticas de interpelação que convocam os indivíduos a ocupar lugares enquanto sujeitos sociais e os processos que constroem subjetividades que formam os sujeitos aos quais se podem fazer esse chamamento. Para assumirem suas identidades, os indivíduos são sempre chamados a assumirem posições de sujeito que Ihes são atribuídas no interior desses discursos, sujeitando-se, negociando-se ou transgredindo-se suas regras; ou tornando-se portadores dos seus sentidos e de suas representações. 
Entre a lógica do sistema produtivo e as lógicas dos usos, medeiam os gêneros. São suas regras que configuram basicamente os formatos, e nestes se ancora o reconhecimento cultural dos grupos. [...] gênero não é algo que ocorre no texto, mas sim pelo texto, pois é menos questão de estrutura e combinatórias do que de competência. [...] um gênero é, antes de tudo, uma estratégia de comunicabilidade, e é como marca dessa comunicabilidade que um gênero se faz presente e analisável no texto (2001, p. 313-314).

Na segunda, o Grupo de Pesquisa Processos de Significação Televisual: gêneros e formatos (GPTV/PPGCOM/UNISINOS) tem dialogado com estudos como os realizados por François Jost (2004b), para quem os produtos televisivos oscilam entre três mundos: real, ficção e lúdico ${ }^{2}$. Nenhum produto, hoje, pode ser tomado como exemplo puro de um dos mundos. No caso da televisão, por exemplo, uma emissora transmite todo tipo de programa, inclusive aqueles que mesclam aspectos ficcionais e não ficcionais. Por isso, Jost investiu num conceito que desse conta dessas emissões de modo a ampliar o campo de visão para a compreensão das narrativas televisivas. Esse conceito é 0 de gênero televisual. Ele o desenvolve a partir da definição de um campo comum sobre o qual se desdobram as estratégias do realizador e os horizontes de expectativas do receptor, sem, no entanto, afirmar que ambas as perspectivas sejam finamente partilhadas. Elas se assentam no que 0 autor denominou como promessa do gênero, oferecida pelo emissor, e sobre a adesão ou não do público a ela. Uma comédia, por exemplo, tem o objetivo de fazer rir. A função do gênero seria fixar o grau de existência do programa em relação ao telespectador, sendo que 0 "gênero é uma promessa global sobre esta relação que vai propor um quadro de interpretações global aos atores ou aos acontecimentos representados em palavras, em sons ou em imagens" (JOST, 2004b, p. 35).

Elizabeth Duarte, ao denominar os gêneros televisivos como macro-articulações semânticas capazes de abrigar produtos com poucas características em comum, compreende-os

Como um feixe de traços de conteúdo da comunicação televisiva que só se atualiza e realiza quando sobre ele se projeta uma forma de conteúdo e de expressão - representada pela articulação entre subgêneros e formatos, esses sim procedimentos de construção discursiva que obedecem a uma série de regras de seleção e combinação (2006, p. 22).

Para Duarte, os subgêneros seriam da ordem da atualização e os formatos da realização, trazendo as especificidades dos programas

Para os fins da análise aqui proposta, não faria muito sentido convocar este terceiro "mundo", nem delinear a discussão entre realidade e ficção. Basta apenas esclarecer que essas formas de apresentação se diferenciam na medida em que a realidade discursiva a) referencia diretamente o mundo exterior, como no caso do telejornal; b) é ficcional como nas telenovelas e séries; c) é criada artificialmente não tendo como referência o mundo exterior. Compreendemos que a televisão não mostra a realidade e, sim, apresenta-a de forma própria, bem como acreditamos que o universo ficcional tem possibilidades tão próximas da realidade quanto outras (MARQUES, 2007). Além disso, não podemos deixar de citar as repercussões dos meios de comunicação em geral nos acontecimentos do mundo, bem como as realidades construídas nos próprios meios como, por exemplo, o real artificial dos reality shows. 
(cenários e configurações) e seriam, também, procedimentos de construção discursiva.

Propomos abordar nosso objeto a partir das contribuições dessas duas perspectivas. Se 0 trabalho de Jost (2004a; 2004b) está baseado na análise semiótica da produção e recepção de produtos mediáticos ${ }^{3}$, a abordagem inspirada nos estudos culturais, sobretudo nas contribuições de Stuart Hall (2000; 2003), também explora um viés interpretativo, ainda que no início das pesquisas a inspiração seja advinda da semiologia estruturalista muito em voga nos anos $70^{4}$. Mas se Hall afirma que "é na forma discursiva que a produção e circulação dos produtos comunicativos acontece e é também na forma discursiva que seu consumo se dá" (GOMES, 2002, p. 169), é possível entrever aí uma dinâmica de interpretação na qual a recepção ocupa o lócus central.

Concordamos com Gomes quanto ao fato de que os gêneros

[...] são formas reconhecidas socialmente a partir das quais se classifica um produto dos media. [...] Colocar a atenção nos gêneros implica reconhecer que o receptor orienta sua interação com o programa e com o meio de comunicação de acordo com as expectativas geradas pelo próprio reconhecimento do gênero" (idem, p. 182).

Mas, também pensamos que os gêneros, ao oferecerem uma promessa, enriquecem 0 entendimento, pois são convenções pelas quais a maneira de significar dos programas é estruturada, determinando regras e limites para o processo de produção. Compreendê-los dessa maneira permite-nos identificar como significados e acontecimentos são codificados na feitura de determinado produto cultural.

\subsection{As potencialidades da análise de conteúdo}

Tendo em vista a questão proposta: "quais são as posições de sujeitos moradores de favelas construídas pelas narrativas televisivas?", propomos uma análise de conteúdo articulada ao gênero ao qual cada programa pertence, com vistas a capturar a recorrência dos termos e sua contribuição para os processos de significação do mesmo.

A análise de conteúdo (AC) é definida por Albert Keintz (1973, p. 51) como uma "técnica de pesquisa para a descrição objetiva e rigorosa

0 próprio Jost afirma em entrevista publicada na Revista Fronteiras (2004a, p. 172) que "Peirce não estava no início de minhas investigações. Eu havia elaborado uma tipologia tripartite dos mundos da televisão: real, ficcional e lúdico. [...] Um peirceano me fez perceber, um dia, que eu estava seguindo Peirce sem saber... Levei a observação a sério e me dei conta de que minha trilogia estava bastante próxima do modelo triádico de Peirce e que este me autorizava a fundar minhas reflexões sobre bases semióticas sólidas. [...] os mundos não são nada mais, nada menos que os interpretantes".

Estamos atentas ao fato de que os estudos culturais ingleses têm-se baseado na semiótica de matriz estruturalista ou pósestruturalista. No entanto, seguimos as pistas deixadas por Gomes (2002) ao afirmar que "fazer dialogar os cultural studies e a semiótica é também explorar as consequências e assumir os riscos de levá-los a dialogar com a semiótica de matriz peirceana e trabalhar com a hipótese de que parte das limitações atuais reconhecidas aos estudos culturais deve-se à opção pela semiologia" (p. 174) 
do conteúdo das comunicações". A AC passa por uma caracterização do conteúdo e permite, por exemplo, descrever e analisar o que 0 autor chama de modelos-padrões, ou seja, as representações sobre os sujeitos e o modo como são classificados. Para Martin Bauer (2002), a vantagem da $\mathrm{AC}$ é a de viabilizar a classificação sistemática de uma grande quantidade de material em uma descrição curta de suas características, possibilitando que o contexto que conforma os textos seja analisado. Segundo esse autor (idem, p. 191) a AC "é uma técnica de produzir inferências de um texto focal para 0 seu contexto social de uma maneira objetivada". A representação é reconstruída a partir de duas dimensões principais. A primeira é em relação à sintaxe (frequência de palavras, vocabulário etc.) e a segunda em relação à semântica (o que é dito em um texto?).

Os dados da AC propiciam uma descrição geral do texto analisado. Contudo, para que não se restrinja a isso, propomos um processo analítico realizado em dois movimentos, um quantitativo e um qualitativo. 0 primeiro é a organização dos termos e de sua frequência de aparição em uma tabela. Desse modo, é possível verificar quais são os termos dominantes para se referir às favelas e a seus moradores. A limitação desse primeiro momento encontra-se no fato de que o resultado careceria de uma profundidade analítica. A
AC diz pouco sobre 0 modo como a posição de sujeito foi construída. A solução encontra-se no segundo movimento: caracterizar o gênero ao qual o programa está vinculado como chave de interpretação dos dados.

Metodologicamente, resta esclarecer que 0 procedimento da AC é comumente utilizado para análise de textos impressos. Porém, nossa proposta consiste em adotá-lo para textos televisivos e, sendo assim, deparamo-nos com um objeto de estudo complexo que se insere na lógica da televisão e do seu fluxo. Para dar conta de tal desafio, baseamo-nos no trabalho de Diane Rose (2002) que realizou uma pesquisa sobre representações da loucura na TV britânica a partir da AC. Para tanto, ela selecionou alguns operadores descritivos que dessem conta da dimensão audiovisual do seu objeto: os mapas de codificação dos elementos audiovisuais.

\section{Caracterização do corpus, operadores descritivos e categorias de análise}

A escolha do programa - o primeiro ano da série Cidade dos Homens, exibido pela Rede Globo de Televisão - deu-se a partir de um fenômeno observado na relação entre os media e a sociedade, qual seja, a midiatização da violência nos espaços das favelas ${ }^{5}$. Além disso, ele alcançou índices de audiência significativos e seu roteiro trata de modo específico da vida nas 
favelas e de seus moradores ${ }^{6}$. Para a construção dos mapas dos elementos textuais optamos por um referencial que procurasse atender à questão central da pesquisa? Tal problema possui duas palavras-chave: "moradores", que faz referência a sujeitos, e "favela", que se refere a um lugar. Assim foram estabelecidos dois operadores descritivos como referenciais de codificação:

a) sujeitos: incluímos todas as palavras que se referem aos sujeitos vinculados diretamente às favelas (inclusive pronomes pessoais e nomes próprios - que foram alocados de acordo com os sujeitos aos quais faziam referência) e elegemos os seguintes termos: morador de favela; favelado; traficante; criminoso; culpado; vítima; suspeito; trabalhador. 0 termo "outros" refere-se aos sujeitos não considerados pertencentes às favelas, como policiais, moradores de outras localidades;

b) lugar: incluímos todas as palavras que se referem ao lugar "favela" e destacamos os seguintes termos: comunidade; favela/morro; periferia; lugar de violência; lugar da ausência e da falta; escassez simbólica (ausência de projetos culturais, equipamentos sociais etc.); lugar do caos (a polícia não entra, o Estado não controla); cidade. 0 termo "outros" refere-se a lugares como Brasil, EUA, Iraque etc.

A elaboração do mapa dos elementos audiovisuais seguiu o estudo realizado por Rose (2002), dada a importância de se levar em conta os ambientes nos quais as cenas ocorrem, bem como uma descrição pormenorizada da narrativa analisada. Adotamos os seguintes operadores:

a) ambiente de cena: descrição dos principais ambientes nos quais as cenas se desenrolam: internos (estúdio, casas, delegacias etc) e externos (ruas, praças, praias etc.);

b) descrição da narrativa: descrição da história narrada: quem narra, o fio condutor, o momento de clímax, a resolução. Descrição dos movimentos de câmeras, trilha sonora, iluminação, etc., para que seja possível compreender o quanto elementos visuais contribuem no posicionamento dos sujeitos.

Para a análise construímos duas categorias: "modos de apresentação dos sujeitos", para evidenciar qual é a posição que os discursos constroem quando representam os moradores de favelas, e "lugar das favelas", para captar qual seria a posição atribuída pelas narrativas; se são tratadas como exógenas ou

Para evidenciar as duas primeiras dimensões do processo comunicativo, foi feita a análise do primeiro episódio do primeiro ano da série. Além de ser um procedimento exaustivo, julgamos que a análise dos demais não seria relevante, uma vez que a série foi veiculada em uma única semana, englobando seus episódios numa mesma proposta.

Julgamos necessário evidenciar as várias maneiras pelas quais as favelas e seus moradores vêm sendo representados. Estudos desenvolvidos nas Ciências Sociais (VALADARES, 2005; SILVA, 2002; RINALDI, 1998; ZALUAR; ALVITO, 1998) indicam pelo menos dois eixos preferenciais de representação. 0 primeiro é a noção de ausência pelo qual a favela é definida pelo que ela não é e não possui: um espaço destituído de infra-estrutura urbana, sem leis, regras ou ordem - uma expressão do caos. Outro eixo é o da homogeneização, ou seja, desconsidera-se a historicidade e as peculiaridades de cada espaço favelado e a homogeneidade se torna a tônica quando se trata de representá-lo. Dessa homogeneidade surgiu uma das representações sociais mais fortes em relação aos sujeitos moradores: a de serem criminosos em potencial. Conforme Silva $(2002$, p. 8) há, também, uma visão romântica segundo a qual os moradores de favela seriam encarados como "vítimas passivas e intrinsecamente infelizes de uma estrutura social injusta". 
pertencentes à cidade e a relação que se estabelece entre lugar e sujeitos. Em seguida, apresentaremos a análise do programa.

\subsection{Como Cidade dos Homens apresenta as favelas e seus moradores?}

A série Cidade dos Homens, protagonizada por

Darlan Cunha e Douglas Silva, foi exibida em quatro temporadas entre 2002 e 2005, às sextasfeiras, às 22h30min, num total de 19 episódios. Ela trata do cotidiano de Laranjinha e Acerola, que vivem em uma favela carioca com problemas como o tráfico de drogas, a violência, a carência material e os preconceitos. Analisamos o primeiro episódio, "A Coroa do Imperador", que foi ao ar na semana da criança, em 2002, e que traça um paralelo entre as guerras napoleônicas e as guerras nas favelas pelo tráfico de drogas.

0 site da emissora ${ }^{8}$ indica 0 gênero série de entretenimento. Nele, as imagens são coloridas e alegres, o que aponta para um tom leve e juvenil, apesar de também tratar da violência e do tráfico. Os protagonistas são crianças e pré-adolescentes, e 0 lançamento foi na semana do dia das crianças, confirmando esse aspecto pretendido. 0 programa parece ser mais bem classificado como série brasileira. Série, por ter começo, meio e fim em cada episódio, sendo desnecessário conhecimento prévio da história, ainda que isso enriqueça a forma como o telespectador a recebe. E brasileira por tratar de tema do cotidiano nacional. Contudo, o programa contém ainda algumas características de documentário, como tratar de assunto do cotidiano sob perspectiva crítica e aprofundar-se em tema específico, como a vida de crianças e adolescentes das favelas. No episódio analisado, a utilização de tais imagens é realçada no momento em que os atores, na posição de si próprios, e não mais dos personagens que representam, fazem relatos sobre suas experiências com a violência. Esse momento é bem demarcado: a luz é mais crua, azulada; do cenário, não aparecem mais os móveis, o fundo é escuro. 0s garotos falam como se estivessem dentro de um documentário, contando suas experiências. Junto a suas imagens, aparecem subtítulos com seus nomes reais e suas idades. Esses relatos cessam, restando apenas um eco. Luz e cores, assim como o cenário, voltam a sua forma anterior. Podemos classificar Cidade dos Homens na categoria

Quadro 1: síntese dos elementos de codificação textual em Cidade dos Homens

\begin{tabular}{|l|c|l|c|}
\hline \multicolumn{2}{|c|}{ SUJEITO $\left(\mathbf{n}^{\circ}\right.$ de ocorrências durante o programa) } & \multicolumn{2}{c|}{ LUGAR $\left(\mathbf{n}^{\circ}\right.$ de ocorrências durante o programa) } \\
\hline Morador de favela & 165 & Comunidade & 3 \\
\hline Favelado & 0 & Favela/morro & 34 \\
\hline Traficante & 170 & Periferia & 0 \\
\hline Criminoso & 9 & Lugar de violência & 42 \\
\hline Culpado & 0 & Lugar da ausência e da falta & \\
\hline Vítima & 8 & Escassez simbólica & 0 \\
\hline Suspeito & 0 & Lugar do caos & 0 \\
\hline Trabalhador & 14 & Cidade & \\
\hline Outros (policiais, moradores de outras localidades etc) & 154 & Outros (outras localidades que não sejam as favelas) & 43 \\
\hline
\end{tabular}


entretenimento, no gênero teledramaturgia e no sub-gênero série brasileira.

Quanto aos modos de apresentação dos sujeitos, notamos que são posicionados de maneira positiva. Não se trata mais do "favelado" estereotipado, termo que não teve ocorrência. Na época de lançamento da série na TV, o diretor Fernando Meirelles assumiu que ela dava continuidade ao filme Cidade de Deus, mas que o enfoque seria dado aos moradores das favelas e suas rotinas:

Cidade de Deus narra a formação do tráfico organizado nos morros cariocas. Os traficantes são o tema do filme, e, como pano de fundo, vemos as comunidades aprendendo a lidar com a nova ordem. Cidade dos Homens é o outro lado. 0 filme trata de um aspecto da vida de uma comunidade do Rio, a questão das famílias desorganizadas, e o tráfico é que faz o pano de fundo. A série é um complemento. [...] Nesta série, a comunidade é 0 destaque. [...] 0 público sempre se interessou pelo assunto. 0 fato é que dificilmente a TV e o cinema mostravam o lado dos marginalizados (MEIRELES apud SAITO, 2002).

A linguagem também foi objeto de discussão entre os produtores. Segundo Guel Arraes, diretor do núcleo responsável pela série, a linguagem adotada deveria enfatizar "o conflito interno de meninos pobres assediados pelo tráfico de drogas.

Daí integrar os atores da ONG Nós do Cinema, criada para que os 200 jovens que atuaram no filme "Cidade de Deus", todos de comunidades pobres do Rio, não ficassem sem rumo após as filmagens." Para Kátia Lund, criadora da ONG e uma das diretoras da série, 0 fato de ter sido produzida como cinema e rodada em película deu uma cara distinta ao programa dentro da grade da Globo.
Nesse sentido, aparece no ponto de vista dos produtores uma proposta de posicionar os protagonistas como "moradores", e o programa 0 faz em contraste com a existência de traficantes, termo frequente 170 vezes, mas, acima de tudo, 0 faz evidenciando a vida cotidiana - de mães, pais, avós, pessoas honestas e solidárias. Estes últimos foram contabilizados nas 165 ocorrências do termo "morador de favela" e 14 do termo "trabalhador", como a professora da escola, as empregadas domésticas etc. Não podemos deixar de mencionar 0 alto número de ocorrências do termo "traficante", uma vez que ele aparece inserido em várias situações exibidas na narrativa. 0 traficante (e os vários nomes próprios referentes), além de aparecer nas cenas de disputa pelos pontos de droga, é também apresentado como aquele que estabelece outras relações com as pessoas do local. É uma obra ficcional que "promete" o entretenimento, mas que dá a ver um pouco da complexidade das relações nas favelas. É possível observar que a posição conferida aos sujeitos não se enquadra apenas nas visões hegemônicas - como as dos indivíduos fadados ao crime ou totalmente passivos e vítimas diante da realidade que os cerca. Tanto o é que termos como "suspeito" e "culpado" não ocorrem no programa e "criminoso" e "vítima" ocorrem apenas nove e oito vezes, respectivamente.

Quanto ao lugar das favelas, houve a tentativa de fazer uma apresentação mista deste universo. Na verdade, o termo "favela" não foi evitado, como atestado pelas 34 ocorrências. Contudo, as 
favelas não são definidas pela falta, referência que não foi encontrada. Tampouco são apenas o lugar do caos, da ausência e da homogeneização. Elas não são todas iguais e as relações dentro delas não são ignoradas. Em grande parte do tempo de exibição (aproximadamente 1/3) as personagens aparecem frequentando espaços que não têm nenhuma relação evidente com a violência ou 0 tráfico. São ambientes familiares e de trabalho. Por outro lado, a violência não é negligenciada: ela aparece 42 vezes quando se descreve o "lugar das favelas" na narrativa. Mas a violência aparece de modo mais direto nas cenas que mostram Acerola sendo assaltado, nas cenas do rebuliço causado pelo tiroteio na zona comercial da favela e na longa sequência de depoimentos dos atores. As outras cenas incluídas nessa temática são as que se passam nas bocas de fumo ou nas cenas de animação que explicam as origens e 0 desenrolar dos embates entre os dois bandos rivais.

Apesar de as favelas terem sido mostradas como apartadas da cidade, aqui elas não foram representadas apenas negativamente a partir do contraste com a cidade - termo mencionado apenas oito vezes. Podemos entender isso tendo em vista que as "favelas" e a "cidade" foram apresentadas por meio do olhar daqueles que moram nas favelas, demonstrando uma perspectiva diferente das produções que mostram tais espaços sempre associados à violência, à falta e ao caos.

Mas será que essa estratégia realmente encontra eco nas interpretações feitas por adolescentes que moram nas favelas? Como a estruturação de grupos de discussão pode nos auxiliar não só a perceber as negociações dessas interpretações, mas também o modo como 0 processo de questionamento e troca de pontos de vista permite uma objetivação da condição marginalizada desses adolescentes, para que eles possam, de alguma forma, agir sobre ela?

\section{A produção de sentidos em grupos de discussão}

Os grupos de discussão são basicamente entrevistas em grupo, cujo foco principal reside na interação do grupo, e não no mero intercâmbio de perguntas e respostas entre o pesquisador e os integrantes do grupo. ${ }^{9} \mathrm{~A}$ interação entre os membros do grupo está baseada em tópicos específicos que são trazidos pelo pesquisador que geralmente assume o papel de moderador do grupo.$^{10}$ Segundo Morgan, nos grupos de discussão

0 uso do termo "grupos de discussão" difere-se da concepção usualmente associada ao termo "grupos focais", ou seja, a uma perspectiva ligada a pesquisas de marketing ou modos de consumo em que pouco interesse é conferido à dinâmica intersubjetiva estabelecida entre os participantes. Apesar de adotarem o termo "grupos focais", a maioria dos pesquisadores que empregam esse método nas Ciências Sociais confere especial destaque à importância de se observar o modo coletivo de construção dos discursos e não sua mera expressão individual (KITZINGER,1994; DUCHESNE; HAEGEL, 2004; WARR, 2005).

Não desconsideramos o fato de que as dinâmicas que perpassam o grupo de discussão são marcadas pelo conflito e pela autoridade, sobretudo entre o moderador e os participantes. Mas uma co-produção, seja de sentidos, de identidades ou de normas é sempre perpassada pela tensão entre hegemonia e resistência. Contudo, a atividade dialógica do grupo expressa um desafio a ambos: construir conjuntamente conhecimentos e compreensões a respeito daqueles que dividem conosco um mundo comum, ainda que representativamente cindido. 
"os participantes fazem perguntas uns aos outros e explicam suas posições de forma recíproca" (1996, p. 139). Assim, os grupos de discussão

[...] provêm a oportunidade de observar os participantes conduzindo seus próprios testes discursivos, negociando sentidos, confirmando ou desafiando modos apropriados de percepção. [...] Eles podem revelar premissas cognitivas ou ideológicas que estruturam argumentos, os modos como vários discursos estão enraizados em contextos particulares e experiências específicas são trazidas à tona nas interpretações que marcam a construção discursiva das identidades sociais (LUNT; LIVINGSTONE, 1996, p. 88 e 96).

Ao utilizarmos tal metodologia, temos em mente construir uma análise mais complexa da recepção. Tal análise parte do pressuposto, amplamente difundido e corroborado por diversas pesquisas (FISKE,1994; LOPES, 2002; JACKS,1999; GOMES, 2005), segundo o qual a recepção é socialmente construída e diferenciada, mas que vai além da ideia do receptor ativo. 0 processo de recepção deve ser articulado a práticas político-culturais que motivam a reflexão crítica e a problematização da fala cotidiana a partir do universo simbólico difundido pelos media. 0 questionamento de estereótipos e concepções de fundo torna-se possível, sobretudo quando os media veiculam representações de grupos de sexualidade estigmatizada, moradores de favela, negros, dentre e outros.
Os procedimentos que guiaram a realização dos grupos estruturaram-se do seguinte modo: ao identificarmos que Cidade dos Homens era uma narrativa construída a partir da visão de seus protagonistas, Acerola e Laranjinha, decidimos procurar adolescentes para participarem dos grupos de discussão. Em seguida, como nosso propósito era o de discutir sobre a construção político-cultural da identidade dos moradores de favela - a questão das posições de sujeito - procuramos jovens que tivessem algum engajamento político na comunidade no intuito de compreender como essa mediação os auxilia na construção de sua visão de mundo, de seu auto-entendimento e de sua auto-identidade. E, por último, pretendíamos analisar em que medida aquela série, que claramente fazia referência aos morros do Rio de Janeiro, seria interpretada por um público, também morador de favela, mas de outra cidade, no caso, Belo Horizonte.

Foram estruturados dois grupos: um no Rio de Janeiro, com adolescentes que faziam parte do grupo ECO ${ }^{11}$, no Morro Santa Marta, local onde foi filmada a maior parte da série; e outro em Belo Horizonte, em uma favela da Barragem Santa Lúcia com adolescentes que faziam parte do programa Agente Jovem ${ }^{12}$. Em ambos os grupos os adolescentes tinham entre 15 e 18 anos.

Ver 0 site: < http://www.grupoeco.org.br/>.

12 Esse programa é fruto da parceira de ONG's com a Prefeitura Municipal de Belo Horizonte e objetiva oferecer uma alternativa aos adolescentes no período em que não estão na escola. Os jovens se reúnem três vezes na semana com uma programação que envolve discussões e debates dos temas acima descritos, além de atividades esportivas. No caso do Grupo Eco (RJ), os adolescentes se reúnem semanalmente, com uma dinâmica que inclui maior entrosamento no grupo, discussão de temas relevantes como política de um modo geral, a importância das ações coletivas e da vida na comunidade, debates sobre filmes, drogas, saúde, sexualidade etc. 
Realizamos, nos meses de outubro, novembro e dezembro de 2005, dois grupos de discussão em cada favela que constavam da exibição dos episódios do primeiro ano da série Cidade dos Homens seguida da discussã $0^{13}$.

\subsection{0 morro na televisão}

Os adolescentes que compuseram os grupos em Belo Horizonte e no Rio de Janeiro reagiram, em um primeiro momento, de modo divergente. Se, para os adolescentes da Barragem Santa Lúcia, o que a série mostrava "não era verdade", para os adolescentes do Morro Santa Marta, aquela representação condizia com a realidade vivida no morro. Os movimentos de identificação ou estranhamento realizados pelos adolescentes com relação à série foram feitos utilizando como parâmetros as noções de violência e tráfico de drogas:

Carlos: [A série] só mostrou o lado feio da favela, o lado sujo, o lado obscuro da favela. Não mostrou as outras coisas que a favela tem.

Mara: Até pelo próprio horário que o programa foi exibido. Será que era tão violento que teria que ser exibido àquela hora? Por quê? Na favela só tem violência? E por que então que a gente tá aqui?

José: Eu acho que sim porque só mostrou muita arma, mostrou muita droga na favela. E não é só isso, não é tanto assim.

Ana: Mas, eu acho interessante ver filme assim, mostrando a favela, a realidade que a gente vive (Grupo focal Barragem Santa Lúcia, BH).
A associação entre cotidiano vivido, drogas e violência é entendida pelos adolescentes do Rio como rotineira. Contudo, assim como os adolescentes de Belo Horizonte, eles afirmam que o morro não se reduz a esses elementos. Para eles, a série, mesmo voltada para a representação da vida cotidiana através da inserção de preocupações e dramas ligados à família, à escola e ao trabalho, não consegue apresentar de forma adequada os aspectos positivos da favela:

Cláudia: Eu não acho que esse tipo de preocupação demonstra o lado positivo da favela. Porque se você pegar qualquer criminoso que tá aqui, lógico que se preocupa com a mãe. Do mesmo jeito que uma pessoa normal se preocupa com a mãe. Não acho que existe um lado positivo específico da favela.

Vera: Até quando você falou da amizade entre o Acerola e Laranjinha, que o Laranjinha deu 0 dinheiro para o outro, mesmo assim a amizade levou o Laranjinha a fazer uma coisa ruim, que foi ir na boca pedir dinheiro.

Lili: 0 problema é que, da maneira que eles mostram, a impressão que dá é que a maioria do morro é assim, mas não é isso, sabe? É a minoria, entendeu? 0 pessoal trabalha, o pessoal desce, estuda, nem tem tempo pra ficar de brincadeira no meio do caminho.

Paulo: Até o lado bom, o lado que poderia ser bom foi uma coisa meio... 0 seguinte: na escola, mostrava eles na escola, mas você viu que não mostrou em momento nenhum eles assistindo uma aula decente?

Lili: Sempre tumultuada.

Os grupos de BH contaram com dez participantes cada, e no RJ, os grupos variaram entre três e seis participantes. A dinâmica de cada encontro foi orientada por um roteiro semi-estruturado de perguntas agrupadas em três eixos: a) o morro na televisão; b) os moradores de favela na televisão; c) é possível uma mobilidade simbólica: morro e asfalto e não morro x asfalto? Optamos por mudar o nome dos adolescentes que integraram nossa pesquisa de modo a preservar seu anonimato. Para mais detalhes ver Marques e Rocha (2006). 
Paulo: Tumultuada, bolinha de papel, 0 que a professora falava não dava certo.

Lili: A professora nem respondia o que eles perguntavam.

Paulo: Professora histérica, gritando. Isso pode ser até realidade para algumas pessoas, mas [...] não é só porque mora na favela que se torna um favelado (Grupo focal Morro Santa Marta, RJ).

As falas dos adolescentes Lili e Paulo novamente refletem o quanto o modo de representação da favela se entrelaça com a percepção do morador da favela. 0 sentido desvalorizante do termo "favelado" é algo que eles tentam questionar a todo instante. 0 debate em torno dessas questões criou oportunidades para que os participantes pudessem, no momento da discussão, expor criticamente seus pontos de vista, confirmar algum sentido já compartilhado, pensar sobre 0 que estava sendo dito e reconhecer a importância que representações como essas podem ter ao subsidiar a imagem que será construída por aqueles que não são moradores de favela.

\subsection{Os moradores de favela na televisão}

A associação entre "moradores de favela" e "marginais" foi identificada pelos adolescentes das duas cidades como aquela responsável pela violência simbólica por eles enfrentada. 0 estereótipo que os associa à marginalidade revela-se como um dos grandes empecilhos tanto à construção um auto-entendimento positivo quanto à luta pelo reconhecimento alheio.

Eva: Não, teve o lado positivo também. Foi 0 sentimentalismo, também, né? Dos meninos.
Foi bom para as pessoas verem que quem mora na favela também tem sentimentos.

Mara: Mas, será que as pessoas precisam que passem na televisão para elas verem isso?

Carlos: Igual eu já falei. Muitas pessoas que moram lá embaixo, que tem dinheiro, acham que todo mundo que mora aqui é marginal, que todo mundo que mora aqui é ladrão, safado, sem vergonha, que não tem nada para fazer. Mas, não é assim. Tem gente que trabalha, tem gente que quer ver seu filho crescer. Tem muitos universitários nesse bairro aqui. A gente aqui não é só malandro. Malandro aqui, vamos dizer, não é nem $1 \%$; 2 ou $1 \%$. 1,5\%. [...]

Moderador: Vocês acham que lá o tráfico está mais presente...

Carlos: Bom, aqui é menos, aqui é diferente, aqui [BH]é menos perigoso do que lá [RJ]. Eu estou falando menos perigoso assim, menos violento. Lá o tráfico é mais pesado do que aqui. Não tem como falar que não é (Grupo focal Barragem Santa Lúcia, BH).

A oposição feita pelo participante Carlos entre "aqueles que moram lá embaixo", no asfalto, e "aqueles que moram aqui em cima", no morro, acentua uma das dimensões do processo de construção da identidade: a demarcação da diferença. Categorias como "nós" e "eles", "aqui" e "lá" apontam não só as distinções elaboradas pelos próprios adolescentes, como aquelas identificadas nas representações presentes em Cidade dos Homens. Assim, falar sobre a série, ou melhor, inserir-se em um debate sobre ela, é um movimento que auxilia na constituição do entendimento que os adolescentes possuem da própria identidade, uma vez que eles negociam - por meio da troca recíproca de argumentos 
- entendimentos sobre como se inserem e

como participam de relações sociais e políticas

enquanto "moradores de favela".

A identidade não se deixa reduzir à sua

"encenação" no espaço de visibilidade midiática, por isso, desafiar as representações que a televisão oferece e investir em narrativas que desestabilizam os estereótipos é uma maneira de lutar por novos entendimentos sobre 0 "morador de favela". Nessa perspectiva, as discussões realizadas nos grupos do RJ foram muito interessantes porque, ao se verem na $\mathrm{TV}^{14}$, os adolescentes puderam tanto identificar-se com quem são, e com a comunidade onde vivem, quanto afastarem-se daquela representação ao dizerem o que faltava nela e como queriam ser vistos.

Paulo: Não me surpreende, pois o que mostra no filme para mim já é uma realidade. Me surpreenderia se mostrasse outra coisa [...]. Do jeito que foi colocado no filme, daqui a pouco a gente vai ter que comprar um guarda-chuva blindado, porque vai ser chuva de bala direto. [...] Sinceramente, se a ideia base fosse aproximar a favela e o pessoal do asfalto, na minha opinião. eu acho que eles fizeram um péssimo trabalho. Porque não foi bom.

Carol: Se o filme mostrasse o lado positivo da favela seria até legal, porque só mostra a criminalidade direto, como se fosse o dia-a-dia. Não passou os projetos que tem na favela, as ONGs, a família, a união que nem sempre é muita, mas também tem. Não, não passa. Só passa criminalidade.

Lili: Eu acho que realmente eles pecaram porque não mostraram tanto as coisas boas da favela. Só que eles falaram que mostraram, por exemplo, quando aparece o garoto indo pra escola, a relação ali, mas é pouquíssimo. Isso aí é muito pouco. [...] Exageraram o outro lado. Então, acabou ficando uma imagem de que favela só tem marginal, que a criança tem contato com a criminalidade muito cedo. (Grupo Focal Morro Santa Marta, RJ).

Os participantes, ao serem interpelados pelas posições de sujeito oferecidas pela série complexificaram suas identidades tanto admitindo a violência quanto reivindicando um outro lado da vida em comunidade que gera solidariedade e que, na sua opinião, não foi retratado em Cidade dos Homens.

\subsection{A oposição entre "morro" e "asfalto"}

De modo geral, tanto os adolescentes da Barragem Santa Lúcia quanto os do Morro Santa Marta identificaram como "fracassada" a tentativa empreendida pelos realizadores de Cidade dos Homens de aproximar o morro e 0 asfalto através da identificação de dramas e vivências comuns a esses dois mundos. Para eles, a série privilegiou a violência e seus desdobramentos e não se encarregou de mostrar 0 "outro lado" da vida no Morro, um lado que procura se distanciar dessa

A participação dos adolescentes do Morro Santa Marta na elaboração de capítulos da série Cidade dos Homens, tanto na elaboração dos roteiros quanto na atuação em alguns episódios (e até mesmo na improvisação das cenas) implicou um desafio ao tipo de representação estereotipada ligada à noção de favelados, em favor de uma representação mais multifacetada (moradores de favela). 0 questionamento do estereótipo ocorre na medida em que aqueles diretamente afetados por ele também puderam lançar mão de sua visão de mundo e de seus códigos compartilhados para entrar na construção desse diálogo representacional. Contudo, é preciso frisar: trata-se de uma representação transformada em ficção para a TV. Não há um realismo ingênuo, nem tampouco se trata de um documentário. 
violência, embora conviva com ela, privilegiando a vida em comunidade.

0 participante Lucas acentua que, ao assistir a uma série como esta, ele procura "se encontrar naquela situação mostrada" ao invés de desafiar a própria resistência a representações que fogem ao lugar comum. Ou seja, ele aponta que "as pessoas" preferem justificar seus argumentos e sua opinião com base na ideia pré-concebida segundo a qual, quando a televisão representa a favela, $o$ faz apenas com 0 intuito de denegrir sua imagem, de "piorar as coisas", de passar uma ideia de que "lá" seria um verdadeiro caos: a lei do tráfico, o império do medo.

Todavia, o fato de ter formulado verbalmente essa resistência, tornando-a acessível ao restante do grupo, revela também um movimento reflexivo capaz de dar início à desestabilização dos estigmas que tanto os oprimem. Desafiar as representações que a televisão oferece corriqueiramente e investir na descoberta e no uso de recursos discursivos próprios é algo que alcança sua potencialidade quando esses adolescentes, por meio da troca argumentativa, procuram configurar sua identidade e a do morador de favela de um modo mais complexo que, ao mesmo tempo, lida com a presença da violência e do tráfico e procura evidenciar outras dimensões do cotidiano centradas no repúdio à criminalidade.

A nosso ver, as dinâmicas argumentativas desencadeadas pelo grupo de discussão atuam como mediação na produção de sentido a partir do momento em que os participantes passam a elaborar coletivamente 0 significado de sua própria participação na comunidade em que vivem e na sociedade como um todo.

\section{Conclusão}

Em Cidade dos Homens, as posições de sujeito oferecidas foram basicamente duas: trabalhador honesto que consegue sobreviver apesar dos infortúnios; ou aquele que escolhe uma vida marginal, associada ao tráfico e à criminalidade. Elas, a nosso ver, permaneceram afinadas com a promessa contida no gênero: entretenimento que possibilita alguma ousadia nas representações que questionam aquelas hegemonicamente edificadas segundo a qual a favela é o lugar da falta, do caos e da ausência. Contudo, não se esquivou de apresentar aqueles sujeitos de modo condizente com tais discursos hegemônicos: a favela é lugar de criminoso e marginal, ainda que nesse programa haja uma expansão dessa representação nas tentativas de aproximação dos traficantes com os moradores.

A adesão dos adolescentes participantes dos grupos de discussão, no entanto, parece não ter correspondido plenamente às expectativas dos realizadores. Como pudemos ver, houve resistência às representações oferecidas, ora para reivindicar o que faltava, ora para criticar o que excedia. E, como as posições de sujeito dependem do investimento do próprio sujeito, é adequado supor que há brechas pelas quais se pode resistir, 
negar ou mesmo transformar o sentido de um discurso e ressignificá-lo de forma positiva.

Nesse sentido, quando uma posição de sujeito, tida anteriormente como modelo pré-estruturado inquestionável - no qual os adolescentes procuram, em um primeiro momento, se adequar - é questionada, há um esforço conjunto para romper a resistência enraizada em pressupostos e pré-conceitos.

Acreditamos que a abordagem dos momentos do modelo de promessa de gênero -estratégias dos produtores e a adesão ou não do público; possibilidades reflexivas que as narrativas mediáticas nos oferecem; e questionamento acerca do processo de formação de identidades - só foi possível graças ao nosso investimento num percurso de pesquisa complexo que tomou o processo comunicativo por base; que se esforçou tanto por evidenciar a linguagem específica da televisão quanto captar os processos mesmos de interpretação dos diversos sujeitos diretamente concernidos pelas representações ali oferecidas.

\section{Referências Bibliográficas}

BAUER, Martin. Análise de conteúdo clássica: uma revisão. Pesquisa qualitativa com texto, imagem e som. In: ; Gaskell, G. (eds.). Petróplis: Vozes, 2002. p. 189-217.

DUARTE, Elisabeth. Reflexões sobre os gêneros e formatos televisivos. Televisão: entre 0 mercado e a academia. In: CASTRO, M. L.D.; DUARTE, E.B. (orgs.). Porto Alegre: Sulina, 2006. p. 19-30.

DUCHESNE, Sophie; HAEGEL, Florence. La polititisation des discussions, au croisement des logiques de specialisation et de conflictualisation.

Revue française de Science Politique, Paris, v.54, n.6, p. 877-909, déc. 2004.

FISKE, John. Media matters: everyday culture and political change. Minneapolis: University of Minnesota Press, 1994.

GOMES, Itânia Maria Mota. Das utilidades do conceito de modo de endereçamento para análise do telejornalismo. In: DUARTE, E.B.; CASTRO, M.L.D. (orgs.). Televisão: entre 0 mercado e a academia. Porto Alegre: Sulina, 2006. (v. 1) p. 107-123.

GOMES, Itânia Maria Mota. A investigação do processo comunicativo em duas tradições de investigação sobre os media. Rio de Janeiro: E-papers, 2005.

GOMES, Itânia Maria Mota A noção de gênero televisivo como estratégia de interação: 0 diálogo entre os cultural studies e os estudos da linguagem. Revista Fronteiras, São Leopoldo, v. IV, n. 2, p. 165-185, dez. 2002.

HALL, Stuart. Codificação/Decodificação. In:

Da diáspora. Belo Horizonte: UFMG, 2003. p. 387-404.

HALL, Stuart. Quem precisa da identidade? In: SILVA, Tomás Tadeu da (org.). Identidade e diferença: a perspectiva dos estudos culturais. Petrópolis: Vozes, 2000. p. 103-133.

JACKS, Nilda. Querência: cultura regional como mediação simbólica. Porto Alegre: UFRGS, 1999.

JOST, François. Entrevista. Revista Fronteiras, São Leopoldo, v. VI, n. 1, p. 169-174, jan.-jun. 2004a.

JOST, François. Seis lições sobre televisão. Porto Alegre: Sulina, 2004b.

KIENTZ, Albert. A análise de conteúdo aplicada aos media. Comunicação de massa: análise de conteúdo. Rio de Janeiro: Eldorado, 1973. p. 51-73.

KITZINGER, Jenny. The methodology of focus groups: the importance of interaction between research participants. Sociology of Health and Illness, West Sussex, v.16, n.1, p. 103-121, 1994. 
LOPES, Maria Immacolata Vassalo. Vivendo com a telenovela. São Paulo: Summus, 2002.

LUNT, Peter; LIVINGSTONE, Sonia. Rethinking the focus group in media and communication research. Journal of Communication, Washington DC, n. 46, vol. 2, p. 79-98, 1996.

MARQUES, Ângela. Ficção, cotidiano e narrativa: entre 0 visto e 0 vivido. Revista de Estudos da Comunicação, Curitiba, v.8, n.15, p. 29-39, jan.-abr. 2007.

; ROCHA, Simone Maria. A produção de sentidos nos contextos de recepção: em foco o grupo focal. Revista Fronteiras, São Leopoldo, v. 8, n.1, p. 38 - 53, jan./abr. 2006. MARTÍN-BARBERO, Jésus. Dos meios às mediações. Rio de Janeiro: UFRJ, 2001.

MORGAN, David. Focus Groups. Annual Review of Sociology, Palo Alto CA, v. 22, p. 129-152, 1996.

RINALDI, Alessandra. Marginais, delinqüentes e vítimas: um estudo sobre a representação da categoria favelado no tribunal do júri da Cidade do Rio de Janeir". In: ZALUAR, Alba; ALVITO, Marcos (orgs.). Um século de favela. Rio de Janeiro: FGV, 2003. p. 299-322.

ROCHA, Simone Maria; MARQUES, Ângela. A interseção do processo comunicativo: um diálogo entre produção e recepção. In: JACKS, Nilda; SOUZA, Maria Carmem Jacob (Org.). Mídia e Recepção: televisão, cinema e publicidade Salvador: EdUFBA, 2006. p. 32-55.

ROSE, Diana. Análise de imagens em movimento. In: BAUER, M.; Gaskell, G. (eds.). Pesquisa qualitativa com texto, imagem e som: um manual prático.

Petrópolis: Vozes, 2002. p. 343-364.

SAITO, Bruno Yutaka. Cidade dos Homens complementa filme. Folha de S. Paulo, Ilustrada, São Paulo, p. E6, 15 out. 2002.

SILVA, J. Um espaço em busca de seu lugar: a favela para além dos estereótipos. 2002. Disponível em: $<$ www.iets.inf.br/acervo/Artigos.htm>. Acesso em: 06 nov. 2007.
SOUZA, Maria Carmen Jacob de. Mediações na recepção: qual seria mesmo a importância da análise do lugar dos realizadores? Contracampo, Niterói, v. 10/11, n.40/41 p. 11-123, 2004.

VALLADARES, L. A invenção da favela: do mito de origem à favela.com. Rio de Janeiro: FGV, 2005.

WARR, Deborah. It was fun...but we don't usually talk about these things. Analyzing sociable interactions in focus groups. Qualitative Inquiry, Illinois, v. 11, n.2, p. 200-225, 2005.

ZALUAR, A.; ALVITO, M. (orgs). Introdução. In: Um século de favela. Rio de Janeiro: FGV, 1998. p. 07-24. 


\section{From gender promise to reflexive interpretation: perspectives for television narratives analyses}

\section{Abstract}

This article aims to present and discuss an integrated analysis of television products, focusing on different dimensions of the communicative process: production, product and reception. We search to evidence the interlocutions among them from a methodological approach that articulates: a) content analysis and television gender analysis and b) a media product reception analysis in discussion groups. In order to test our methodological proposal we empirically employ it in a dramaturgical television gender study focusing on the subject positions (HALL, 2000) about inhabitants of Brazilian slum quarters constructed by media narratives. The three analytical dimensions have been used to understand the ways these inhabitants are presented and the place occupied by slum quarters in those narratives. Furthermore we also investigate the interpretations produced by slum quarter's inhabitants concerning the television series Cidade dos Homens (Rede Globo, 2002) through discussion groups carried out in two Brazilian cities: Rio de Janeiro and Belo Horizonte.

\section{Keywords}

Communicative process. Integrated methodology. Television narratives. Subject positions.
De la promesa de género a la interpretación reflexiva: perspectivas para el análisis de las narrativas televisivas

\section{Resumen}

Este artículo presenta un análisis integrado de productos televisivos, enfocando las diversas dimensiones del proceso comunicativo: producción, producto y recepción. Buscamos evidenciar las interlocuciones entre ellos a partir de un abordaje metodológico que articula: a) análisis del contenido y análisis de género televisivo y el b) análisis de la recepción de un producto mediático en grupos de discusión. Aplicamos empíricamente esta metodología al género de la dramaturgia televisiva, concentrando en las posiciones del sujeto (HALL, 2000) construidas por las narrativas mediáticas referentes a los habitantes de las favelas brasileñas. Las tres dimensiones analíticas son utilizadas con la intención de entender las maneras de presentación de estos habitantes y del lugar de lasfavelas en esas narrativas. Además, estudiamos las interpretaciones que ellos producen sobre la serie Cidade dos Homens (Rede Globo, 2002) reunidos en grupos de discusión realizados en dos ciudades brasileñas: Rio de Janeiro y Belo Horizonte.

\section{Palabras clave}

Proceso comunicativo. Metodología integrada. Narrativas televisivas. Posiciones del sujeto. 


\section{Expediente}

A revista E-Compós é a publicação científica em formato eletrônico da Associação Nacional dos Programas de Pós-Graduação em Comunicação (Compós). Lançada em 2004, tem como principal finalidade difundir a produção acadêmica de pesquisadores da área de Comunicação, inseridos em instituições do Brasil e do exterior.
E-COMPÓS I www.e-compos.org.br I E-ISSN 1808-2599

Revista da Associação Nacional dos Programas de Pós-Graduação em Comunicação. Brasília, v.12, n.1, jan./abr. 2009.

A identificação das edições, a partir de 2008 passa a ser volume anual com três números.

\section{CONSELHO EDITORIAL}

\section{Afonso Albuquerque}

Universidade Federal Fluminense, Brasil

Alberto Carlos Augusto Klein

Universidade Estadual de Londrina, Brasi

Alex Fernando Teixeira Primo

Universidade Federal do Rio Grande do Sul, Brasil

\section{Alfredo Vizeu}

Universidade Federal de Pernambuco, Brasil

Ana Carolina Damboriarena Escosteguy

Pontifícia Universidade Católica do Rio Grande do Sul, Bras

Ana Silvia Lopes Davi Médola

Universidade Estadual Paulista, Brasil

André Luiz Martins Lemos

Universidade Federal da Bahia, Brasil

Ângela Freire Prysthon

Universidade Federal de Pernambuco, Brasil

Antônio Fausto Neto

Universidade do Vale do Rio dos Sinos, Brasil

Antonio Carlos Hohlfeldt

Pontifícia Universidade Católica do Rio Grande do Sul, Brasil

Arlindo Ribeiro Machado

Universidade de São Paulo, Brasil

César Geraldo Guimarães

Universidade Federal de Minas Gerais, Brasil

Cristiane Freitas Gutfreind

Pontifícia Universidade Católica do Rio Grande do Sul, Brasil

Denilson Lopes

Universidade Federal do Rio de Janeiro, Brasil

Eduardo Peñuela Cañizal

Universidade Paulista, Brasi

Erick Felinto de Oliveira

Universidade do Estado do Rio de Janeiro, Brasil

Francisco Menezes Martins

Universidade Tuiuti do Paraná, Brasil

Gelson Santana

Universidade Anhembi/Morumbi, Brasi

Hector Ospina

Universidad de Manizales, Colômbia

leda Tucherman

Universidade Federal do Rio de Janeiro, Brasil

Itania Maria Mota Gomes

Universidade Federal da Bahia, Brasil

Janice Caiafa

Universidade Federal do Rio de Janeiro, Brasil

Jeder Silveira Janotti Junior

Universidade Federal da Bahia, Brasil
João Freire Filho

Universidade Federal do Rio de Janeiro, Brasil

John DH Downing

University of Texas at Austin, Estados Unidos

José Luiz Aidar Prado

Pontifícia Universidade Católica de São Paulo, Brasil

José Luiz Warren Jardim Gomes Braga

Universidade do Vale do Rio dos Sinos, Brasil

Juremir Machado da Silva

Pontifícia Universidade Católica do Rio Grande do Sul, Brasil

Lorraine Leu

University of Bristol, Grã-Bretanha

Luiz Claudio Martino

Universidade de Brasília, Brasil

Maria Immacolata Vassallo de Lopes

Universidade de São Paulo, Brasil

Maria Lucia Santaella

Pontifícia Universidade Católica de São Paulo, Brasil

Mauro Pereira Porto

Tulane University, Estados Unidos

Muniz Sodre de Araujo Cabral

Universidade Federal do Rio de Janeiro, Brasil

Nilda Aparecida Jacks

Universidade Federal do Rio Grande do Sul, Brasil

Paulo Roberto Gibaldi Vaz

Universidade Federal do Rio de Janeiro, Brasil

Renato Cordeiro Gomes

Pontifícia Universidade Católica do Rio de Janeiro, Brasil

Ronaldo George Hela

Universidade do Estado do Rio de Janeiro, Brasil

Rosana de Lima Soares

Universidade de São Paulo, Brasil

Rossana Reguillo

Instituto Tecnológico y de Estudios Superiores do Occidente, México

Rousiley Celi Moreira Maia

Universidade Federal de Minas Gerais, Brasil

Sebastião Carlos de Morais Squirra

Universidade Metodista de São Paulo, Brasi

Simone Maria Andrade Pereira de Sá

Universidade Federal Fluminense, Brasil

Suzete Venturelli

Universidade de Brasília, Brasil

Valério Cruz Brittos

Universidade do Vale do Rio dos Sinos, Brasil

Veneza Mayora Ronsini

Universidade Federal de Santa Maria, Brasil

Vera Regina Veiga França

Universidade Federal de Minas Gerais, Brasil
COMISSÃO EDITORIAL

Ana Gruszynski I Universidade Federal do Rio Grande do Sul, Brasil

Rose Melo Rocha I Escola Superior de Propaganda e Marketing, Brasil

CONSULTORES AD HOC

Alberto Schneider I Visitante Tokyo University

Alexandre Rocha da Silva I Universidade Federal do Rio Grande do Sul, Brasil

Fernanda Bruno I Universidade Federal do Rio de Janeiro, Brasil

Ida Stumpf I Universidade Federal do Rio Grande do Sul, Brasil

Kati Caetano I Universidade Tuiuti do Paraná, Brasil

Laura Cánepa I Universidade Anhembi Morumbi, Brasi

Malena Contrera I Universidade Paulista, Brasil

Sandra Gonçalves I Universidade Federal do Rio Grande do Sul, Brasil

Vicente Gosciola I Universidade Anhembi Morumbi, Brasil

REVISÃO DE TEXTO E TRADUÇÃo I Everton Cardoso

EDITORAÇ̃̃o ELETRÔNICA I Raquel Castedo
COMPós I www.compos.org.br

Associação Nacional dos Programas de Pós-Graduação em Comunicação

Presidente

Erick Felinto de Oliveira

Universidade do Estado do Rio de Janeiro, Brasil erickfelinto@uol.com.br

Vice-presidente

Ana Silvia Lopes Davi Médola

Universidade Estadual Paulista, Brasil

asilvia@faac.unesp.br

Secretária-Geral

Denize Correa Araújo

Universidade Tuiuti do Paraná, Brasil

denizearaujo@hotmail.com 